\title{
ARTICLE \\ SOLUTION WITH MODIFIED PERCEPTRON TO TUNNEL CUTTING FACE EVALUATION PROBLEMS
}

\author{
Yuji WATANABE ${ }^{1}$, Tatsuo KITAJIMA ${ }^{2}$, Masaki KIMURA ${ }^{3}$ and Kenichi HARADA ${ }^{4}$ \\ ${ }^{1}$ Department of Information and Control Engineering, Yamagata College of Industry and \\ Technology, 2-2-1 Matsuei, Yamagata-shi, 990-2473, Japan. \\ E-mail:watanabe@astro.yamagata-cit.ac.jp \\ ${ }^{2}$ Department of Bio-System Engineering, Faculty of Engineering, Yamagata University, 4-3-16 \\ Jonan, Yonezawa-shi, Yamagata 992-8510, Japan. \\ ${ }^{3}$ Kansai Branch, OYO Corporation, 2-4-66 Tagawakita, Yodogawa-ku, Osaka 532-0021, Japan. \\ ${ }^{4}$ Faculty of Art, Kyoto University of Art and Design, 2-116 Uryuyama, Kitashirakawa, Sakyo- \\ ku, Kyoto 606-8271, Japan.
}

(Received: 23 November 2005; Accepted: 21 April 2006)

\begin{abstract}
Up to now, tunnel cutting face evaluation problems have tended to incorporate the engineer's subjective views, and have not agreed with empirical knowledge. As utilizing subjective views as well as empirical data is also effective from the viewpoint of engineering, we studied mechanisms for making tunnel cutting face evaluations using the professional engineer's empirical data. Since tunnel cutting face evaluation problems are simply pattern recognition problems, we decided to utilize neural network technology by artificially reproducing empirical data on computers. Using this technology, the back-propagation method is commonly used for pattern recognition. However, this method has some defects, such as falling into a local minimum. In this study, we traced back to the perceptron, which no longer attracts attention, and found that the defects of the back-propagation method can be solved by modifying it. We then applied this modified perceptron to tunnel cutting face evaluation problems and concluded that this method is useful.

Key words : Pattern recognition, Neural network, Back-propagation method, Linearly separation impossibility problem, Logic circuit, Two-point separation method
\end{abstract}

\section{Introduction}

In tunnel construction, evaluation of the base rock is an important work stage and an essential daily procedure for observing the tunnel cutting face to obtain the grade for deciding the pattern of tunnel supports. The Japan Highway Public Corporation $(\mathrm{JH})$ method, based on the Rock Mass Rating (RMR) method, is commonly used to obtain the grade objectively and quantitatively. Using this method, observation of the cutting face is first divided into six categories (compressive strength, weathering alteration, fissure interval, fissure condition, groundwater discharge, and degradation), and each category is divided into five grades. Preliminary base marks and adjustment marks are assigned for each category. Next, during observation of the cutting face, the grade of each observation item is determined; thus, the total of evaluation mark is obtained automatically. However, two problems exist under the present conditions. One is that decision of the grade tends to incorpo- rate the engineer's subjective view, and the other is that the preliminarily assigned base mark and adjustment mark of each grade may not agree with the engineer's empirical data. Commonly, rock mass classification (e.g., cutting face) evaluation involves subjective judgments based on the engineer's experience (Shimizu et al., 1986). Although subjective views are conventionally excluded to achieve an objective evaluation, incorporating such subjective views and empirical data is also effective from the viewpoint of engineering.

We propose a method of obtaining the total of evaluation mark based on a professional engineer's empirical data. This method is similar to the JH method. However, it differs in that, with regard to the six cutting face evaluation items, the total mark on the grade of the pertinent cutting face are prescribed by the engineer before observation of the cutting face. Furthermore, if it is possible for computers to learn this information, it will become possible to retrieve the engineer's empirical 
data at any time. This method is simply pattern recognition, so we began this study by focusing on neural network technology as a model of information processing in the brain.

The back-propagation method is commonly used for pattern recognition (Rumelhart et al., 1986). Perceptrons, the pioneer of neural network technology, involves the linear separation impossibility problem. The back-propagation method was the central model in the second neural network boom. This method has been applied to various pattern recognition problems including character recognition; however, defects of this method, such as its tendency to fall into a local minimum, have been revealed, in spite of its effectiveness (Baba et al., 1994). These defects are caused by the steepest descent approach of the learning algorithm in use; various solutions have been proposed, but a complete solution has not yet been found.

In this study, we examined the perceptron to eliminate the defects of the back-propagation method. The perceptron was proposed by Rosenblatt (1962) in the latter half of the 1950s as a machine to perform pattern recognition. It used a combination of neuron-like units of McCulloch and Pitts, and performed learning by applying Hebb's learning rules. This became the central model in the first neural network boom, lasting ten years. However, in 1969, Minsky and Papert (1993) proved mathematically that the perceptron is basically a learning machine that enables linear separation; however, linear separation is impossible in some cases. Depending on the case, the number of intermediate units may become huge, and the convergence is too slow. This theory is commonly known as the "limitation of the perceptron". As a result, interest in the perceptron diminished rapidly. However, this model is now the starting point of studies of neural network technology involving learning functions with teacher data. Therefore, if linear separation becomes possible by devising the components of the perceptron, such as the network model and learning algorithm, it is possible to overcome the defects of the back-propagation method. In this study, we examine a new modified method that enables linear separation on the extension of the perceptron. First, we show that the exclusive OR problem, which is typically used for explaining the linear separation impossibility problem, can be solved by using this new two-point separation method. We then apply this method to tunnel cutting face evaluation, examine whether or not pattern recognition is possible, and verify that it is more useful than the back-propagation method.

\section{Principle of Perceptron}

Fig. 1 presents an outline of a neuron. Dendrites of each neuron receive signals from other neurons via synapses. Signal transmissions between neurons are affected by electric pulses, changing the state of the neuron that receives the signals. The neuron fires (generates pulses) when the sum of the electric sig- nals received exceeds the threshold, and then transmits such pulses through axons to influence other neurons.

McCulloch and Pitts proposed a neuron-like unit for this neuron in 1943 (Fig. 2). When the unit receives input $x_{i}$, a connective weight with a size of $w_{i}$ is involved. The unit receives the input expressed below.

$$
y=w_{1} x_{1}+w_{2} x_{2}+w_{3} x_{3}+\cdots+w_{n} x_{n}=\sum_{i=1}^{n} w_{i} x_{i}
$$

The state of the unit becomes $z=1$ when y exceeds the threshold $\theta$; if not, $z=0$. This relation can be expressed as follows.

$$
\mathrm{z}=1[y-\theta] \quad \begin{cases}1 & y-\theta>0 \\ 0 & y-\theta \leqq 0\end{cases}
$$

In 1949, Hebb proposed a synapse reinforcement model, in which the transmission efficiency of the synapse changes. In this model, when a neuron fires, the synapse connection that transmitted signals to this neuron is reinforced. If 0 is output when the correct output is 1 , the connective weight between units is increased and the threshold is lowered in this model. This can be expressed as follows.

$$
\begin{aligned}
& \boldsymbol{w} \leftarrow \boldsymbol{w}+\varepsilon \boldsymbol{x} \\
& \theta \leftarrow \theta-\varepsilon
\end{aligned}
$$

Here, $\varepsilon$ is a small positive constant. If 1 is output when the correct output of 0 , the following is performed.

$$
\begin{aligned}
& \boldsymbol{w} \leftarrow \boldsymbol{w}-\varepsilon \boldsymbol{x} \\
& \theta \leftarrow \theta+\varepsilon
\end{aligned}
$$

By repeating the processes expressed by equations (3) and (4), a desired input-output relation (teacher data) can be obtained (Nakano et al., 1995). This perceptron learning rule has already

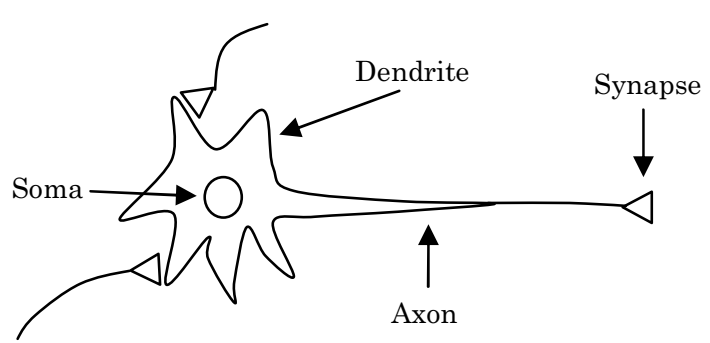

Fig. 1. Outline of neuron.

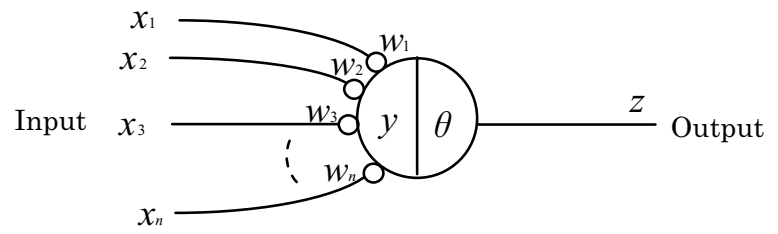

Fig. 2. Neuron-like unit of McCulloch and Pitts. 

perceptron. inequality. tion cannot occur.

been proven as the perceptron convergence theorem (Minsky et al., 1993). In this study, this combination of a single neuronlike unit and the learning rule was regarded as an elementary

\section{Linear Separation Impossibility Problem}

We now consider the case of two inputs and one output. For $z=1$, equations (1) and (2) indicate that an elementary perceptron with two inputs can be expressed by the following linear

$$
w_{1} x_{1}+w_{2} x_{2}-\theta>0
$$

Variations occur, depending on coefficients $w_{1}, w_{2}$, and the constant term $\theta$; the area indicated by hatching in Fig. 3 shows the range of variation. An elementary perceptron with two inputs separates a plane by a straight line. However, this cannot be achieved with only a single elementary perceptron in the two cases of exclusive OR (XOR) and exclusive NOR (XNOR). Assuming that the white circles denote 0 and the black dots denote 1, Fig. 3 represents XOR. Here, it is obvious that separa-

To solve this problem, Rosenblatt examined a perceptron with three layers, including the input layer, by inserting another layer of units. This perceptron is depicted in Fig. 4. The connectivity weight and the threshold of the intermediate units were made random so that learning was performed in the output units. This is commonly called the simple perceptron. This perceptron increased the linear separation capability due to random conver-
$(0,1)$

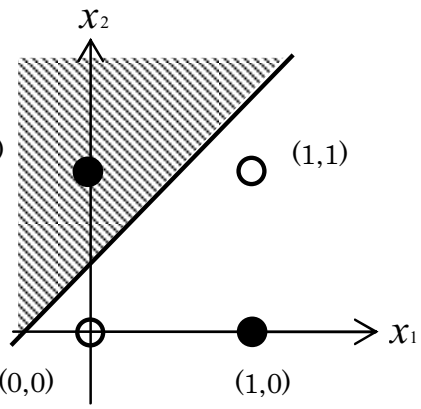

Fig. 3. Linear separation. sion of the intermediate units, but it was not always able to accomplish linear separation.

\section{Two-Point Separation Method}

\subsection{Discussion using logic circuits}

With a single elementary perceptron, it is possible to create logic circuits such as AND and OR, but not XOR or XNOR. If the elementary perceptron is a logic circuit, it seems possible to create XOR through a combination of such circuits.

Table 1 presents a truth table of XOR. The procedure to configure a logic circuit from this truth table is as follows (Niibo et al., 1998). First, a logic formula is established by paying attention to the lines where the output is 1 , assigning $x_{1}$ in the line where the input is 1 or assigning $\bar{x}_{1}$ in the line where the input is 0 , and obtaining the AND of this line. Next, this procedure is performed on every line where the output is 1 and their $\mathrm{OR}$ is assumed to be equal to the output. The logic formula to be obtained is as follows.

$$
z=\bar{x}_{1} \cdot x_{2}+x_{1} \cdot \bar{x}_{2}
$$

This equation is the logic formula of the principal disjunctive canonical form, depicted as a logic diagram in Fig. 5. There is also the method of obtaining the logic formula of the principal conjunctive canonical form. Whichever technique is used, it is the same as the logic circuit; the principal disjunctive canonical form is chosen, and the examination is advanced.

If this logic circuit can be configured using elementary perceptrons, it can achieve linear separation of XOR. In other words, linear separation can be achieved by configuring A', B', and $\mathrm{C}^{\prime}$ of the logic circuit with an elementary perceptron and making them correspond to units $\mathrm{A}, \mathrm{B}$, and $\mathrm{C}$ of the three-layer perceptron (Fig. 4). It is necessary that only units $\mathrm{A}$ and $\mathrm{B}$ in the intermediate units are created by learning while unit $\mathrm{C}$ in the

Table 1. Truth table of XOR.

\begin{tabular}{|c|c||c|}
\hline$x_{1}$ & $x_{2}$ & $z$ \\
\hline \hline 0 & 0 & 0 \\
\hline 0 & 1 & 1 \\
\hline 1 & 0 & 1 \\
\hline 1 & 1 & 0 \\
\hline
\end{tabular}

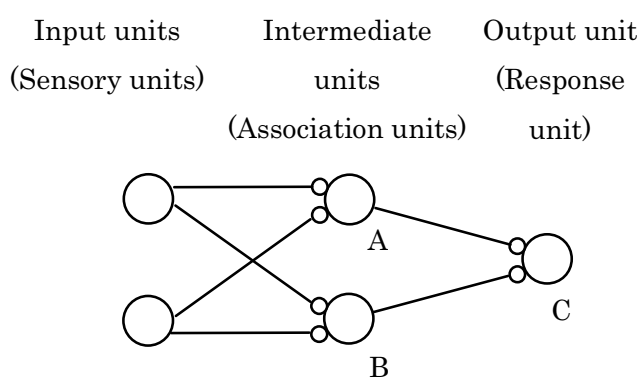

Fig. 4. Three-layer perceptron.

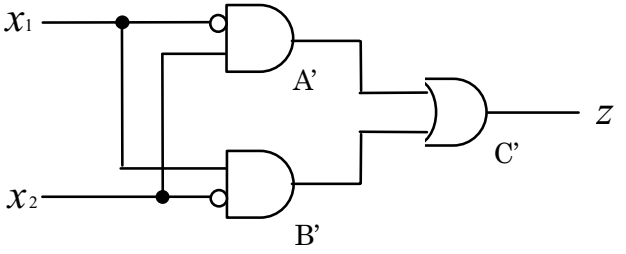

Fig. 5. Logic circuit of XOR. 
output units is fixed to OR. In other words, it is necessary that the perceptron convergence theorem can be applied to units in the intermediate units.

\subsection{Two-Point Separation Method}

Unit $\mathrm{C}$ may be fixed to $\mathrm{OR}$, so its connective weight and threshold are set in advance. Next, units A and B may perform learning to change the connective weight and threshold, depending on the condition of unit $\mathrm{C}$. Therefore, for learning when the output of unit $\mathrm{C}$ is 0 , the outputs of both units $\mathrm{A}$ and $\mathrm{B}$ are reset to 0 . A problem occurs when the output of unit $\mathrm{C}$ is 1 . If learning is performed to set the outputs of units A and B to 1, a contradiction will occur, and creation of the logic circuit presented in Fig. 5 is impossible.

To resolve this problem, we considered making units A and B process only two of the four points. In this two-point separation method, points are divided into two groups, one consisting of $(0,0)$ and $(0,1)$, for example, and the other consisting of $(1,0)$ and $(1,1)$. Unit $A$ is set to cover $(0,0)$ and $(0,1)$, and unit $B$, $(1,0)$ and $(1,1)$. First, as presented in Fig. 6, unit A is set to respond to black dot $(1)$ at $(0,1)$ but not respond to the black dot at $(1,0)$. As a result, separation as indicated by the solid line in Fig. 6, instead of separation indicated by dotted line, becomes possible by learning. The same operation may also be performed for $(1,0)$ and $(1,1)$. The result of this operation, as presented in Fig. 7 and equation (6), is ultimately obtained by con-

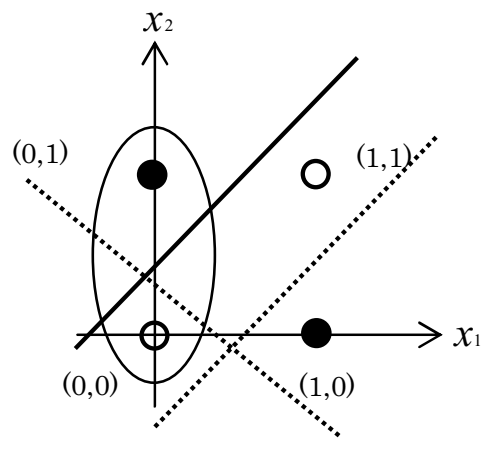

Fig. 6. Two-point separation method.

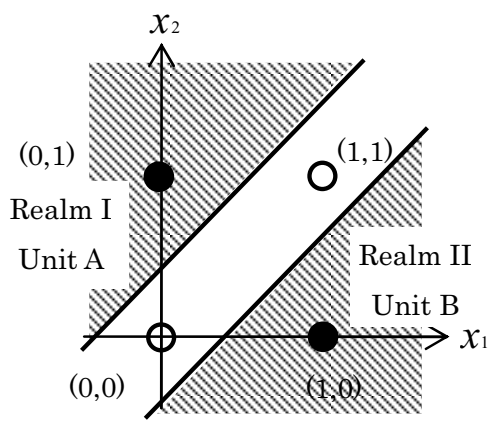

Fig. 7. Separation using two units. necting realm I and realm II with OR.

\subsection{Learning Algorithm}

The learning algorithm of the two-point separation method considering the principal disjunctive canonical form with two inputs and one output is summarized below. This very simple algorithm is composed of the following two cases. Unit $\mathrm{C}$ in the output units is still preliminarily fixed to OR. Learning is performed iteratively until all teacher data satisfy this condition.

( $i$ ) If the output of unit $\mathrm{C}$ is 1 when it should be 0 , learning is performed on the output of unit A or B, whichever is 1 , to reset it to 0 .

(ii) If the output of unit $\mathrm{C}$ is 0 when it should be 1 , the following learning is performed.

Learning to set the output of unit A to 1 for $(0,0)$ and $(0,1)$, or

Learning to set the output of unit B to 1 for $(1,0)$ and $(1,1)$.

\subsection{Discussion of extendibility}

The multiple-input, multiple-output case is considered first. The geometrical figure of the three inputs and one output shown in Fig. 8 represents a cube, and there are 8 input data points. This two-point separation method makes two points at a time. With linear separation, it is necessary that the intermediate layer has four units. When the number of input units is denoted as $n$,

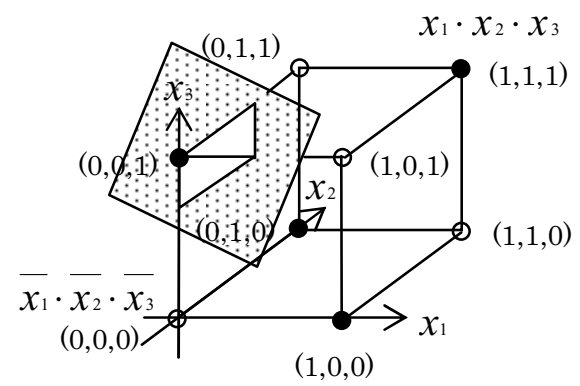

Fig. 8. The case of three inputs.

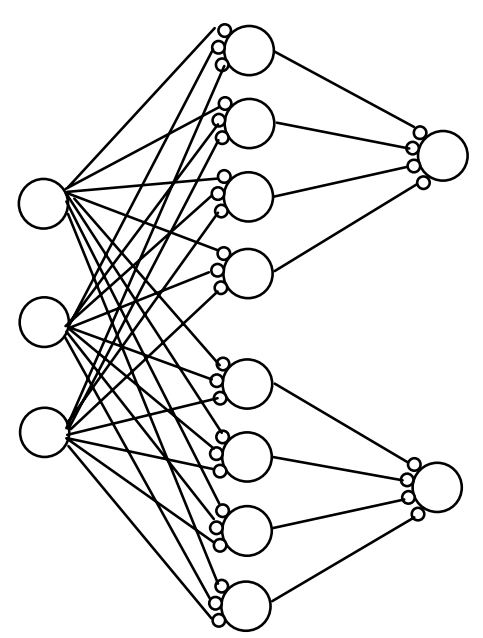

Fig. 9. Network structure (three inputs and two outputs). 
the number of intermediate units is as shown below.

$$
\frac{2^{n}}{2}=2^{n-1}
$$

The discussion of three inputs and two outputs is considered next. The two-point separating method needs intermediate units that become independent for every output unit. Without the network structure shown in Fig. 9, linear separation will not be consistent. If the number of all intermediate units of multiple-input and multiple-output is generalized, the number of input units is denoted as $n$ and the number of output units is denoted as $k$, as indicated below.

$$
k \cdot 2^{n-1}
$$

When there are four inputs, the geometrical figure becomes a four-dimensional hypercube. With four or more inputs, it becomes a hypercube (Niibo et al., 1998), and the linear separation problem becomes a problem of separating each vertex of the hypercube by hyperplanes. The two-point separation method can also be applied, and the learning algorithm mentioned in Section 4.3 can be extended and used.

\section{Application to Tunnel Cutting Face Evaluation Problems}

\subsection{Network Structure}

The two-point separation method was applied to cutting face evaluation data of Tunnel $\mathrm{T}$, and its effectiveness was verified. Six cutting face observation items (compressive strength, weathering, fissure interval, fissure condition, groundwater discharge, and degradation) were adopted. Each item was divided into a maximum of six grades, as indicated in Tables 2 and 3. The total of evaluation mark was obtained as the sum of the base mark and the adjustment mark; the range of the total mark was 0 to 100 , but minus mark was also sometimes given. It is not necessary to give these marks to the neural network directly, just to

\begin{tabular}{|c|c|c|c|c|c|c|c|c|}
\hline \multicolumn{3}{|c|}{ Lithologic Character / Grade } & 1 & 2 & 3 & 4 & 5 & 6 \\
\hline \multirow{4}{*}{ Compressive strength } & \multirow{2}{*}{ Massive } & Hard rock & 36 & 29 & 22 & 14 & 7 & 0 \\
\hline & & Medium hard/soft rock & 32 & 26 & 19 & 13 & 6 & 0 \\
\hline & \multirow{2}{*}{ Bedded } & Medium hard rock & 36 & 29 & 22 & 14 & 7 & 0 \\
\hline & & Soft rock & 39 & 31 & 24 & 16 & 8 & 0 \\
\hline \multirow{4}{*}{ Weathering } & \multirow{2}{*}{ Massive } & Hard rock & 19 & 12 & 6 & 0 & & \\
\hline & & Medium hard/soft rock & 19 & 13 & 6 & 0 & & \\
\hline & \multirow{2}{*}{ Bedded } & Medium hard rock & 22 & 15 & 7 & 0 & & \\
\hline & & Soft rock & 20 & 13 & 7 & 0 & & \\
\hline \multirow{4}{*}{ Fissure interval } & \multirow{2}{*}{ Massive } & Hard rock & 19 & 14 & 9 & 5 & 0 & \\
\hline & & Medium hard/soft rock & 24 & 18 & 12 & 6 & 0 & \\
\hline & \multirow{2}{*}{ Bedded } & Medium hard rock & 9 & 7 & 4 & 2 & 0 & \\
\hline & & Soft rock & 12 & 9 & 6 & 3 & 0 & \\
\hline \multirow{4}{*}{ Fissure condition } & \multirow{2}{*}{ Massive } & Hard rock & 26 & 20 & 13 & 7 & 0 & \\
\hline & & Medium hard/soft rock & 25 & 19 & 12 & 6 & 0 & \\
\hline & \multirow{2}{*}{ Bedded } & Medium hard rock & 33 & 25 & 16 & 8 & 0 & \\
\hline & & Soft rock & 29 & 22 & 14 & 7 & 0 & \\
\hline
\end{tabular}

Table 2. Cutting face evaluation items and base marks.

Table 3. Cutting face observation items and adjustment marks.

\begin{tabular}{|c|c|c|c|c|c|}
\hline \multirow{2}{*}{} & \multicolumn{5}{|c|}{$\begin{array}{c}\text { Grade of groundwater } \\
\text { discharge }\end{array}$} \\
\cline { 2 - 6 } & & 1 & 2 & 3 & 4 \\
\hline \multirow{4}{*}{$\begin{array}{c}\text { Grade of } \\
\text { degradation }\end{array}$} & 1 & 0 & 0 & -5 & -10 \\
\cline { 2 - 6 } & 2 & 0 & -5 & -7 & -10 \\
\cline { 2 - 6 } & 3 & -5 & -7 & -10 & -15 \\
\cline { 2 - 6 } & 4 & -7 & -10 & -15 & -20 \\
\hline
\end{tabular}

Input units Intermediate units Output units

18 units $8 \cdot 2$ units 8 units

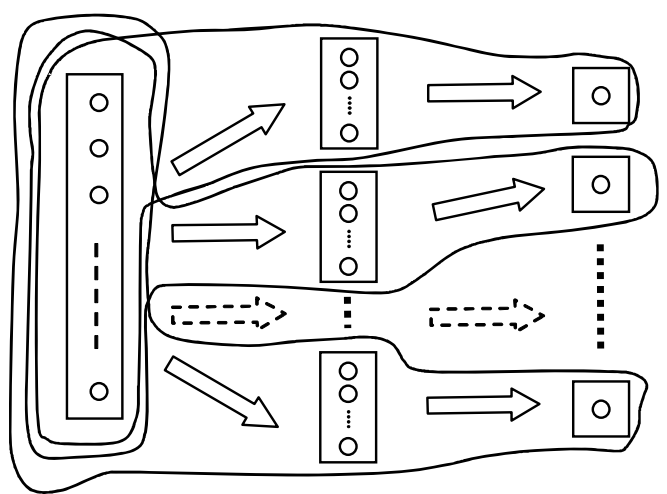

Fig. 10. Network structure. 
match an output numerical value series to an input numerical value series. In this case, an input numerical value series is the value of each evaluation classification; the output numerical value series is the total of evaluation mark. Although Table 2 contains the base marks and Table 3 contains the adjustment marks, it is possible to merge these and to put them into the neural network. In the two-point separation method, binary data consisting of 0 and 1 were adopted exclusively for the input and output units of the neural network, instead of analog data. Examination of the network structure revealed that only three bits (i.e., three units) need be assigned to each item in the input units, so the total number of units was 18 . The output units could be considered in terms of 8-bit signed data, so the number of units was 8 . Next, the number of intermediate units was $8 \cdot 2^{17}=131072$ units from formula (8). Fig. 9 illustrates that the network structure can be extended and considered. This is also depicted in Fig. 10.

Each unit of input units and output units is equivalent to a data bit of the binary number system. Observation items of the cutting face are assigned actual numerical values for the input units as an 18-bit numerical series. The network outputs 8-bit signed data. The 8-bit signed binary number data is converted to a decimal number. It is now possible to describe this neural network structure as a digital logic circuit with a binary number of 0 or 1 . This is equivalent to making this neural network learning using teacher data, i.e., this neural network becomes a combinational logic circuit. This time, we have responded with the integer data form. When the input and output are real numbers, it is possible to perform the process by examining the fixed-point or floating-point data form and making each unit of the network that performs role assignment.

\subsection{Trial Run of Programs}

To determine if cutting face evaluation was possible with the professional engineer's empirical data, we first examined whether the two-point separation method could be applied to the current cutting face evaluation data. We considered that the learning algorithm of the two-point separation method (described in Section 4.3) could be applied. We randomly extracted 100 data points from the 382 data points at the top end portion of Tunnel $\mathrm{T}$. We made it a rule not to select any numerical pattern that had already been selected two or more times. There were 106 types of numerical patterns among these 382 data points. We also conducted a trial run on the program of the back-propagation method as well as that of two-point separation method. (Nakano et al., 1995) Both methods involved the same 100 data points. The first 50 data points were used for learning as teacher data; the remaining 50 data items were used to investigate how the unknown data was estimated. The neural network was checked from two aspects: whether it could learn teacher data that was given, and what output was made for data other than teacher data. Though both methods provided binary data to the neural network, in this case the provided data was first converted into Gray codes that differed by only 1 bit between adjacent codes. Doing so maintained the continuity of numerical patterns in learning by the neural network, producing better results than when no conversion was made.

Teacher data for both methods is listed in Table 4. Unknown data is listed in Table 5. It contains the estimated marks when connective weights and thresholds are set at initial values of 0 by the two-point separation method. Table 6 lists the summary results of the trial run of the program using the twopoint separation method. In the trial run, learning was performed while changing the initial values of connective weights and thresholds; coefficients of correlation with the total of actual evaluation marks were obtained for unknown data. Coefficients of correlation were also obtained for the results of the trial run with the back-propagation method. The results are presented in Table 7. This technique used the steepest descent method, where the connective weights and thresholds were initialized at random and yielded a solution where the error was minimal. The quality of the solution thus tended to be determined by the initial values. Through trial and error, intermediate units were set in two layers. The number of intermediate units was initially layer to 36 and then to 18 . Learning was suspended if the output error of the neural network went below 0.009. Under this condition, the network was capable of learning 50 pieces of teacher data completely, and over-learning was prevented. In the back-propagation method, reproducibility of teacher data continued to increase when over-learning was performed; thus, it tended to go beyond the range of unknown data. With the back-propagation method, a total of nine trial runs were performed, the same number of trial runs as were run with the two-point separation method, and coefficients of correlation were obtained in the same manner. The average number of times of learning was 6087. All the $p$ values of the coefficient in both methods were 0.000 .

\subsection{Discussion}

In the trial runs, the coefficient of correlation was 0.770 for the back-propagation method and slightly lower $(0.749)$ for the two-point separation method. This may be because the intermediate layer must become independent for every output unit and there is no information connection among the intermediate layers in the two-point separation method. However, there is no evidence to clearly show this now. Investigation of this will be the next purely theoretical subject. Anyway, no large differences between the two methods were evident, so it was considered that the performances as a neural network were equal.

We investigated the relation between the output of estimat- 
Table 4. Teacher data.

\begin{tabular}{|c|c|c|c|c|c|c|}
\hline $\begin{array}{l}\text { Compressive } \\
\text { strength }\end{array}$ & Weathering & $\begin{array}{l}\text { Fissure } \\
\text { interval }\end{array}$ & $\begin{array}{l}\text { Fissure } \\
\text { condition }\end{array}$ & $\begin{array}{c}\text { Groundwater } \\
\text { discharge }\end{array}$ & Degradation & $\begin{array}{l}\text { Evaluation } \\
\text { Mark }\end{array}$ \\
\hline 4 & 3 & 4 & 4 & 1 & 1 & 33 \\
\hline 4 & 2 & 2 & 4 & 2 & 1 & 45 \\
\hline 4 & 2 & 5 & 4 & 2 & 1 & 36 \\
\hline 5 & 3 & 4 & 4 & 1 & 1 & 25 \\
\hline 6 & 4 & 5 & 5 & 2 & 2 & -5 \\
\hline 5 & 3 & 4 & 4 & 2 & 2 & 20 \\
\hline 5 & 3 & 5 & 4 & 1 & 1 & 22 \\
\hline 5 & 3 & 4 & 4 & 1 & 2 & 25 \\
\hline 5 & 4 & 4 & 5 & 1 & 1 & 11 \\
\hline 6 & 3 & 5 & 5 & 2 & 2 & 2 \\
\hline 6 & 4 & 5 & 5 & 1 & 2 & 0 \\
\hline 6 & 4 & 5 & 5 & 1 & 1 & 0 \\
\hline 4 & 2 & 4 & 4 & 2 & 2 & 34 \\
\hline 4 & 2 & 4 & 3 & 1 & 1 & 46 \\
\hline 4 & 2 & 5 & 5 & 1 & 1 & 29 \\
\hline 6 & 4 & 4 & 5 & 2 & 2 & -2 \\
\hline 4 & 2 & 2 & 4 & 2 & 2 & 40 \\
\hline 5 & 4 & 5 & 5 & 2 & 3 & 1 \\
\hline 5 & 3 & 5 & 5 & 1 & 2 & 15 \\
\hline 4 & 2 & 5 & 4 & 1 & 2 & 36 \\
\hline 5 & 2 & 5 & 4 & 1 & 2 & 28 \\
\hline 5 & 3 & 5 & 4 & 2 & 2 & 17 \\
\hline 4 & 2 & 4 & 4 & 1 & 1 & 39 \\
\hline 5 & 4 & 5 & 5 & 1 & 1 & 8 \\
\hline 5 & 4 & 5 & 5 & 2 & 2 & 3 \\
\hline 6 & 3 & 4 & 5 & 3 & 4 & -5 \\
\hline 4 & 2 & 4 & 4 & 2 & 1 & 39 \\
\hline 4 & 3 & 3 & 3 & 1 & 1 & 43 \\
\hline 4 & 3 & 5 & 4 & 1 & 1 & 30 \\
\hline 5 & 4 & 4 & 5 & 1 & 2 & 11 \\
\hline 4 & 2 & 2 & 3 & 2 & 1 & 52 \\
\hline 4 & 2 & 4 & 5 & 2 & 2 & 27 \\
\hline 5 & 3 & 4 & 5 & 1 & 1 & 18 \\
\hline 5 & 3 & 5 & 5 & 1 & 1 & 15 \\
\hline 3 & 2 & 3 & 4 & 2 & 1 & 50 \\
\hline 6 & 4 & 4 & 5 & 1 & 2 & 3 \\
\hline 6 & 3 & 4 & 4 & 1 & 1 & 17 \\
\hline 4 & 2 & 4 & 4 & 1 & 2 & 39 \\
\hline 4 & 3 & 5 & 4 & 1 & 2 & 30 \\
\hline 4 & 4 & 5 & 4 & 2 & 2 & 18 \\
\hline 4 & 2 & 3 & 4 & 2 & 2 & 37 \\
\hline 5 & 2 & 5 & 5 & 2 & 2 & 16 \\
\hline 1 & 2 & 2 & 4 & 2 & 1 & 68 \\
\hline 5 & 3 & 4 & 5 & 1 & 2 & 18 \\
\hline 4 & 3 & 3 & 4 & 1 & 1 & 36 \\
\hline 4 & 1 & 3 & 2 & 1 & 1 & 64 \\
\hline 4 & 2 & 3 & 4 & 2 & 1 & 42 \\
\hline 5 & 3 & 4 & 4 & 2 & 1 & 25 \\
\hline 6 & 3 & 4 & 5 & 1 & 1 & 10 \\
\hline 6 & 4 & 5 & 4 & 2 & 2 & 2 \\
\hline
\end{tabular}


Table 5. Unknown data and two-point separation method trial estimated data (for the initial values of connective weight and threshold set to zero).

\begin{tabular}{|c|c|c|c|c|c|c|c|}
\hline $\begin{array}{l}\text { Compressive } \\
\text { strength }\end{array}$ & Weathering & $\begin{array}{l}\text { Fissure } \\
\text { interval }\end{array}$ & $\begin{array}{l}\text { Fissure } \\
\text { condition }\end{array}$ & $\begin{array}{c}\text { Groundwater } \\
\text { discharge }\end{array}$ & Degradation & $\begin{array}{l}\text { Evaluation } \\
\text { mark }\end{array}$ & $\begin{array}{c}\text { Estimated } \\
\text { mark }\end{array}$ \\
\hline 6 & 4 & $\overline{5}$ & $\overline{5}$ & 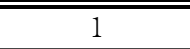 & 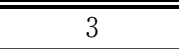 & 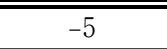 & 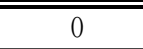 \\
\hline 5 & 4 & 4 & 4 & 1 & 1 & 18 & 24 \\
\hline 5 & 2 & 5 & 5 & 1 & 2 & 21 & 19 \\
\hline 4 & 2 & 5 & 4 & 2 & 2 & 31 & 32 \\
\hline 4 & 4 & 4 & 3 & 1 & 1 & 33 & 45 \\
\hline 2 & 1 & 2 & 3 & 2 & 1 & 74 & 75 \\
\hline 3 & 2 & 3 & 4 & 1 & 1 & 50 & 43 \\
\hline 5 & 3 & 5 & 5 & 2 & 2 & 10 & 15 \\
\hline 5 & 3 & 5 & 4 & 1 & 2 & 22 & 30 \\
\hline 5 & 4 & 5 & 5 & 1 & 2 & 8 & 8 \\
\hline 5 & 2 & 4 & 5 & 1 & 1 & 24 & 0 \\
\hline 4 & 2 & 4 & 3 & 2 & 1 & 46 & 52 \\
\hline 4 & 2 & 4 & 5 & 2 & 1 & 32 & 4 \\
\hline 3 & 2 & 2 & 2 & 2 & 1 & 68 & 50 \\
\hline 4 & 2 & 5 & 4 & 1 & 1 & 36 & 33 \\
\hline 5 & 4 & 4 & 5 & 2 & 2 & 6 & 3 \\
\hline 6 & 4 & 5 & 4 & 1 & 2 & 7 & 30 \\
\hline 5 & 2 & 4 & 4 & 1 & 1 & 31 & 31 \\
\hline 4 & 3 & 5 & 4 & 2 & 2 & 25 & 30 \\
\hline 4 & 2 & 3 & 4 & 1 & 1 & 42 & 36 \\
\hline 3 & 2 & 3 & 5 & 1 & 1 & 43 & 47 \\
\hline 6 & 4 & 5 & 4 & 1 & 3 & 2 & 30 \\
\hline 4 & 1 & 4 & 5 & 1 & 1 & 39 & 24 \\
\hline 4 & 3 & 3 & 4 & 2 & 2 & 31 & 36 \\
\hline 3 & 2 & 2 & 3 & 2 & 2 & 55 & 52 \\
\hline 4 & 3 & 4 & 3 & 1 & 1 & 40 & 46 \\
\hline 4 & 2 & 4 & 5 & 1 & 1 & 32 & 31 \\
\hline 4 & 2 & 3 & 3 & 1 & 2 & 49 & 37 \\
\hline 5 & 2 & 5 & 4 & 1 & 1 & 28 & 30 \\
\hline 5 & 3 & 5 & 3 & 2 & 1 & 29 & 13 \\
\hline 6 & 4 & 4 & 5 & 1 & 1 & 3 & 1 \\
\hline 4 & 3 & 4 & 4 & 2 & 2 & 28 & 35 \\
\hline 6 & 3 & 5 & 4 & 1 & 2 & 14 & 30 \\
\hline 5 & 4 & 5 & 3 & 1 & 1 & 22 & 25 \\
\hline 3 & 1 & 2 & 1 & 1 & 1 & 82 & 85 \\
\hline 5 & 4 & 3 & 4 & 2 & 3 & 14 & 21 \\
\hline 4 & 3 & 4 & 3 & 2 & 2 & 35 & 45 \\
\hline 4 & 4 & 5 & 4 & 1 & 1 & 23 & 29 \\
\hline 6 & 4 & 4 & 5 & 1 & 3 & -2 & 3 \\
\hline 5 & 4 & 5 & 4 & 1 & 2 & 15 & 24 \\
\hline 4 & 2 & 4 & 3 & 1 & 2 & 46 & 43 \\
\hline 5 & 4 & 4 & 4 & 2 & 2 & 13 & 31 \\
\hline 2 & 2 & 3 & 4 & 1 & 1 & 57 & 44 \\
\hline 5 & 2 & 3 & 4 & 2 & 1 & 34 & 58 \\
\hline 3 & 2 & 3 & 1 & 1 & 1 & 72 & 44 \\
\hline 6 & 3 & 4 & 5 & 2 & 2 & 5 & 5 \\
\hline 6 & 3 & 5 & 5 & 2 & 4 & -3 & -5 \\
\hline 4 & 2 & 3 & 5 & 2 & 2 & 30 & 59 \\
\hline 5 & 2 & 4 & 4 & 2 & 1 & 31 & 6 \\
\hline 5 & 3 & 4 & 3 & 1 & 1 & 32 & 22 \\
\hline
\end{tabular}


Table 6. Results of trial run with the two-point separation method.

\begin{tabular}{|c|c|c|c|c|}
\hline & \multicolumn{3}{|c|}{ Threshold } \\
\hline & & -1 & 0 & 1 \\
\hline \multirow{3}{*}{$\begin{array}{c}\text { Connective } \\
\text { weight }\end{array}$} & -1 & 0.773 & 0.523 & 0.565 \\
\hline & 0 & 0.792 & 0.788 & 0.905 \\
\hline & 1 & 0.791 & 0.713 & 0.892 \\
\hline & of & $\begin{array}{l}\text { ents of } \\
\text { dence } \\
9 \pm 0.1\end{array}$ & $\begin{array}{l}\text { elation } \\
\text { val: }\end{array}$ & \\
\hline
\end{tabular}

Table 7. Results of trial run with the back-propagation method.

\begin{tabular}{|c|c|}
\hline $\begin{array}{c}\text { Number of } \\
\text { times }\end{array}$ & Coefficient of correlation \\
\hline \hline 1 & 0.804 \\
\hline 2 & 0.617 \\
\hline 3 & 0.823 \\
\hline 4 & 0.870 \\
\hline 5 & 0.846 \\
\hline 6 & 0.750 \\
\hline 7 & 0.812 \\
\hline 8 & 0.741 \\
\hline 9 & 0.667 \\
\hline Average of coefficients of correlation and \\
$95 \%$ confidence interval: \\
$0.770 \pm 0.065$ \\
\hline \multicolumn{2}{|c|}{} \\
\hline \multicolumn{2}{|c|}{} \\
\hline
\end{tabular}

ed marks by the two-point separation method and the total of expert engineer's evaluation marks. We select the support patterns (B-a, CI-a, CII-a, CII-b, DI-a, DI-b, and DII) from the total of evaluation mark of the cutting face. We examined the coincidence between the two-point separation method outputs and the engineer's evaluations when selecting the support patterns and found that coincidence to be $82 \%$. Although it is still difficult to use this method for engineering, it may be useful for reference trial calculation data.

Learning with the two-point separation method took 76 times more processing time than that with the back-propagation method. In the two-point separation method, the number of intermediate units was fixed. In the relation of $2^{n-1}$ when the number of input units is expressed by $n$, the number of intermediate units increases, leading to an increase in processing time, as pointed out by Minsky and Papert. However, this problem was offset by the progress of computers. In the back-propagation method, however, the number of intermediate layers, the number of intermediate units, and the estimated optimum error had to be determined through trial and error. Moreover, falling into a local minimum was highly probable, depending on the initial values; thus, learning had to be repeated innumerable times until the optimum solution was found. In contrast, with the twopoint separation method, teacher data was able to be learned completely at any time, although performance might vary, depending on the initial values. In other words, the two-point separation method enabled the achievement of linear separation, which was cited as a problem in the "limitations of perceptron". Furthermore, it would not fall into a local minimum and did not require trial and error. Therefore, the two-point method was considered superior to the back-propagation method.

\section{Conclusion}

We studied a solution of tunnel cutting face evaluation problems using neural network technology. This problem is simply a pattern recognition problem, for which the back-propagation method is usually used. However, this method has a few defects, such as the tendency to fall into a local minimum. In this study, we pursued a solution by tracing back to the perceptron, the pioneer of neural network technology. The perceptron has attracted little attention since the "limitation of the perceptron". However, its modification has enabled the achievement of linear separation, thus becoming applicable to tunnel cutting face evaluation problems. This new modified method, the twopoint separation method, allows the learning of all current cutting face evaluation data and obtains a relatively high coefficient of correlation (i.e., 0.749) for unknown data. This method is superior to the back-propagation method as it resolves the problems of the latter (e.g., falling into a local minimum). Moreover, we were changing and trying various combinations of initial values of connective weight and threshold by the twopoint separation method, but we should just evaluate one case in which both of them are set to 0 . For this reason, for an expert in tunnel construction, this method will become simpler and more convenient to use in seeking a solution than the back-propagation method of trial and error. Above all, this is an important result since no algorithm has enabled complete linear separation based on the extension of the perceptron. Thus, engineers can now evaluate cutting faces themselves, provided that values to be evaluated are input as teacher data. We have thus proposed a mechanism that enables successful evaluation based on the professional engineer's empirical data.

\section{References}

Baba, N., Kojima, F. and Ozawa, S. (1994) Basic Knowledge and Application of Neural Network. Kyoritsu Shuppan, Tokyo, 204p.(in Japanese)

Minsky, M. and Papert, S., authors; Nakano, K. and Sakaguchi, Y., translators (1993) Perceptorons, expanded edition. Personal Media, Tokyo, 340p. (in Japanese)

Nakano, K., editor and author (1995) Information System of the Brain Created by C. Kindai Kagaku Sha, Tokyo, 259p.(in Japanese)

Niibo, T. and Matsuo, M.(1998) Introduction to Computers, Ver. 2. Morikita Shuppan, Tokyo, pp.58-63. (in Japanese) Rosenblatt, F.(1962) Principles of Neurodynamics. Spartan 
Books, Washington, D.C., 616p.

Rumelhart, D. E., Hinton, G. E. and Williams, R. J.(1986) Learning Representations by Back-Propagating Errors. Nature, vol.323, no. 6088 , pp.533-536.
Shimizu, N. and Sakurai, S. (1986) A Study on Rock Mass Classification by Fuzzy Set Theory. Journals of the Japan Society of Civil Engineers, no.370 / III-5, pp.225-232.(in Japanese)

\section{要 旨}

\section{トンネル切羽評価問題に対する改良パーセプトロンによる解法}

: 渡辺 雄二 ${ }^{1}$. 北嶋 龍雄 ${ }^{2} \cdot$ 木村 正樹 $^{3}$ - 原田 憲一 ${ }^{4}$

これまでトンネル切羽を評価する際，技術者の主観が混入し易いことや，技術者の経験智にそぐわないことがある という問題があった。主観や経験的デー夕を利用する立場を取ることも工学的には有効であるため，今回，専門技術 者の経験的データで切羽評価を行う仕組みを検討した。切羽評価の問題は，パターン認識の問題そのものであり，解 法は様々であるが，経験的データを人工的にコンピュータ上に再現するという観点を考慮し，ニューラルネットワー ク技術を用いることとした。この技術の中で，パターン認識には一般に誤差逆伝播法が使われている。しかし，これ にはローカルミニマムに陥り易いなどの欠点がある。本研究では，今では注目されなくなってしまったパーセプトロ ンまでさかのぼり，これを改良すれば誤差逆伝播法の欠点が解決できることを見出した。そして，この改良パーセプ トロンをトンネル切羽評価問題に適用し，本手法が有用であることを結論付けた。

キーワード : パターン認識, ニューラルネットワーク, 誤差逆伝播法, 線形分離不可能問題, 論理回路, 二点分離法

${ }^{1}$ 山形県立産業技術短期大学校情報制御システム科％990-2473 山形市松栄 2-2-1

${ }^{2}$ 山形大学工学部応用生命システム工学科 $=992-8510$ 山形県米沢市城南 4-3-16

3 応用地質株式会社関西支社 ₹ 532-0021 大阪市淀川区田川北2-4-66

${ }^{4}$ 京都造形芸術大学芸術学部 $=606-8271$ 京都市左京区北白川瓜生山2-116 